\title{
Analysis of the Behavior of Local Cooking Utensils in Tap Water, Salt Tap Water and Vegetable Oil According to the Temperature
}

\author{
Mamadou Babacar Ndiaye ${ }^{1^{*}}$, Sandrine Bec ${ }^{2}$, Bernard Coquillet ${ }^{2}$, Ibrahima Khalil Cissé ${ }^{3}$ \\ ${ }^{1}$ University Institute of Technology IUT/UT, University of Thies, Thies, Senegal \\ ${ }^{2}$ Laboratory of Tribology and Dynamics of Systems, CNRS UMR 5513, Lyon, France \\ ${ }^{3}$ Laboratory of Materials Mechanical and Hydraulic, Polytechnic School of Thies, Thies, Senegal \\ Email: *mbndiaye@univ-thies.sn
}

Received November 1, 2013; revised November 29, 2013; accepted December 6, 2013

Copyright (C) 2013 Mamadou Babacar Ndiaye et al. This is an open access article distributed under the Creative Commons Attribution License, which permits unrestricted use, distribution, and reproduction in any medium, provided the original work is properly cited.

\begin{abstract}
In Senegal the aluminum scrap are mainly recycled kitchen utensils [1]. The craftsmanship poses the problem of the quality of finished products [1] especially when we know they are used for everyday cooking. Given that none of these alloys should not be used to make cooking utensils if we refer to the EN 601 standard in July 2004, which refers to this regard [1], this study aims at analyzing behavior of these alloys reconstructed in three settings (tap water, vegetable oil and salt water more than 3 grams per liter), chosen for their importance in Senegalese cuisine. Significant loss of material was observed mainly by intergranular corrosion. It would be interesting that additional studies be conducted to examine the impact of the daily use of these alloys on the health of Senegalese.
\end{abstract}

Keywords: Aluminum Alloys; Recycling; Cooking Utensils; Chemical Analysis; Salt Water; Vegetable Oil

\section{Introduction}

In Senegal, artisans use waste aluminum alloys originally developed for the automotive, printing, construction or decoration to make utensils. A previous study has shown that none of the alloys used is suitable for use in the food industry [1]. The objective of this study is to analyze, depending on the temperature, the behavior of these alloys in water, vegetable oil and salt water that are the bases of the Senegalese cuisine.

Corrosion of aluminum is widely studied [2,3]. Studies of the corrosion of aluminum alloys in automotive and industrial environment are numerous [4]. However, studies are significantly lower in the food area of concern. Moreover, in this case, the work focuses on the food put in contact with the materials from which it attempts to value the transfer. Thus a linking of two aspects of the problem is quite innovative.

The expected results should help us to better understand the impacts of the use of these vessels on their service life but also lay the foundation for further studies on

\footnotetext{
*Corresponding author.
}

the health consequences of the Senegalese population.

\section{Materials and Methods}

After studying several years, dozens of representatives of the different mixtures developed for the manufacture of kitchen utensils samples were collected. The results have been presented in a previous study [1].

We have chosen, based on their chemical composition, two (sample $\mathrm{N}^{\circ} 1$ and $\mathrm{N}^{\circ} 3$ ) scale manufacture alloys, pure aluminum plate (Alupur) and aluminum pressure cooker bought in France, which serves as a reference (reference). Samples were designated as follows:

- Sample $\mathrm{N}^{\circ} 1$, which contains low levels of silicon and copper combined with a high rate of magnesium;

- Sample $\mathrm{N}^{\circ} 3$, which differs from the preceding high levels of silicon and copper with a low magnesium level;

- Reference sample, which was developed in Europe following the EN 601 standard in July 2004, which refers in this regard.

These samples come in two forms: 
- Rectangular plates of about $2 \mathrm{~cm}$ square and $2 \mathrm{~mm}$ thick which one surface was prepared by polishing. This allows us to follow the evolution of the surface under the action of different backgrounds. These plates also serve to follow the evolution of the weight loss of samples during the various tests;

- Chips collected by turning from our raw samples. We used them during testing to quantify the mass transfer (colorimetry and plasma spectrometer) to increase the contact surface metal environment. For an average chip thickness of $0.1 \mathrm{~mm}$, the available surface is about $74 \mathrm{~cm}^{2}$ per gram of alloy.

$S_{1}=2 \times$ mass of chip $/($ volumical mass $\times$ chip thickness $)$

$$
=74 \mathrm{~cm}^{2}
$$

In this way, when a rectangular sample of $2 \mathrm{~mm}$ thick and $3 \mathrm{~g}$ of chips of the same material are placed in contact with the test medium in a pyrex container, the total surface in contact with the material is about $231 \mathrm{~cm}^{2}$.

$$
S_{2}=2 \times 2 \mathrm{~cm} \times 2 \mathrm{~cm}+4 \times 2 \mathrm{~cm} \times 0.2 \mathrm{~cm}=9.6 \mathrm{~cm}^{2}
$$

Table 1 summarizes the composition of these samples used for testing food environment.

To mount an operation simulating Senegalese cuisine, we placed the samples in vials pyrex containing:

O: tap water $(250 \mathrm{ml})$ at boiling point $\left(\approx 100^{\circ} \mathrm{C}\right)$;

OS: tap water salted $3 \mathrm{~g} / 1$ at boiling point $\left(\approx 100^{\circ} \mathrm{C}\right)$;

$\mathrm{H}$ : peanut oil $250 \mathrm{ml}, 150^{\circ} \mathrm{C}$.

To avoid the many sources of dispersion inherent in tests performed in the food industry, the following experimental protocol was developed and implemented:

1) The plate and $3 \mathrm{~g}$ of chips are immersed in a Pyrex vessel containing one of the media identified above.

2) At the end of each cooking cycle $(15 \mathrm{mn}+15 \mathrm{mn}+$ $30 \mathrm{mn}$ ), during which additions of distilled water offset the losses due to evaporation, the rectangular sample is removed and rinsed distilled water and then in an ultrasonic bath with alcohol.

3) The cleaned sample is then placed in a stove at $110^{\circ} \mathrm{C}$ for half an hour at least, to remove any moisture before being weighed with a precision balance (the result

Table 1. Chemical composition of the samples.

\begin{tabular}{ccccccc}
\hline & $\mathrm{Si}^{\circ}$ & $\mathrm{Cu}$ & $\mathrm{Fe}$ & $\mathrm{Zn}$ & $\mathrm{Mg}$ & $\mathrm{Mn}$ \\
\hline $\mathrm{N}^{\circ} 1$ & 2.96 & 0.837 & 0.726 & 0.73 & 0.748 & 0.204 \\
$\mathrm{~N}^{\circ} 3$ & 8.330 & 3.430 & 0.777 & 0.602 & 0.183 & 0.172 \\
Alupur & $<0.01$ & $<0.01$ & $<0.01$ & $<0.01$ & $<0.01$ & $<0.01$ \\
Ref & 0.170 & $<0.01$ & 0.62 & 0.032 & $<0.01$ & $<0.01$ \\
\hline & $\mathrm{Cr}$ & $\mathrm{Ti}$ & $\mathrm{Pb}$ & $\mathrm{Sn}$ & $\mathrm{Ni}$ & $\mathrm{Al}$ \\
\hline $\mathrm{N}^{\circ} 1$ & 0.017 & 0.011 & 0.042 & $<0.01$ & 0.08 & rest \\
$\mathrm{N}^{\circ} 3$ & 0.030 & 0.051 & 0.093 & 0.024 & 0.189 & rest \\
Alupur & $<0.01$ & $<0.01$ & $<0.01$ & $<0.01$ & $<0.01$ & rest \\
Ref & $<0.01$ & $<0.01$ & $<0.01$ & $<0.01$ & $<0.01$ & rest \\
\hline
\end{tabular}

is reported to the original surface), and then observed under an optical microscope, scanning electron microscope (SEM: brand Philips XL20 series with the software EDAX) and atomic force microscope (AFM).

The local analysis of the surface made with the AFM after each test step can map the surface relief and provide more detailed information on the formation of cavities and the behavior of different phases during corrosion. Moreover, roughness values, as $\mathrm{R}_{\mathrm{q}}$ index can be obtained from these analyzes. This statistical parameter $\mathrm{R}_{\mathrm{q}}$ is defined as the root mean square deviation of the profile, that is to say, the root mean square value of the heights of the profile within the limits of the basic length.

Colorimetry allowed us to highlight the presence of ions in the substrates. For example through the tricarboxylate aurin ammonium or aluminon in slightly acidic environment, the presence of $\mathrm{Al}^{3+}$ ion gives rise to a red colloidal compound. To avoid false positives, all hazard precautions given in the reference book of G. Charlot [5] were observed.

At last substrate samples were also analyzed by the method of optical emission spectroscopy in inductively coupled plasma.

\section{Results}

The results mainly concern micrography, the variation of the mass and analysis of the presence of ions in the substrates.

\subsection{Micrography}

The observation of the micrographs of all samples shows that some environments such as water and salt water have caused a significant deterioration in the surface samples (Figure 1) contrary to vegetable oil.

\subsection{Roughness}

The observations of the micrography were confirmed by the results for the roughness (Table 2) and the variations in the mass per unit area (Table 3 ).

\subsection{Variation of the Mass}

Measurements of variation of the mass were reported to
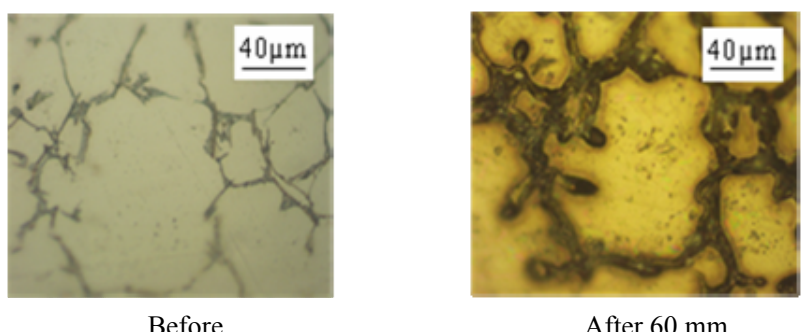

After $60 \mathrm{~mm}$

Figure 1. Micrographs before and after test in salt water. 
Table 2. Results of roughness.

\begin{tabular}{|c|c|c|c|c|}
\hline \multicolumn{5}{|c|}{ Variation of $R_{q}(\mathrm{~nm})$ in tap water } \\
\hline Time (mn) & Alupur & $\mathbf{N}^{\circ} \mathbf{1}$ & $\mathbf{N}^{\circ} 3$ & Ref \\
\hline 0 & 103.9 & 153.4 & 18.78 & 14.15 \\
\hline 15 & 214.6 & 232.3 & 204.3 & 584.2 \\
\hline 30 & 232.8 & 159.5 & 887.5 & 424.5 \\
\hline 60 & 667 & 94.07 & 1058 & 425.5 \\
\hline \multicolumn{5}{|c|}{ Variation of $R_{q}(\mathrm{~nm})$ in salt tap water $(3 \mathrm{~g} / \mathrm{l})$} \\
\hline Time (mn) & Alupur & $\mathbf{N}^{\circ} 1$ & $\mathbf{N}^{\circ} 3$ & Ref \\
\hline 0 & 10.19 & 10.96 & 17.74 & 42.69 \\
\hline 15 & 702.3 & 139.6 & 369.3 & 376.2 \\
\hline 30 & 486.7 & 151.8 & 465.1 & 342.5 \\
\hline 60 & 573.8 & 183.6 & 477.2 & 368.2 \\
\hline \multicolumn{5}{|c|}{ Variation of $R_{q}(\mathrm{~nm})$ in vegetal oil } \\
\hline Time (mn) & Alupur & $\mathbf{N}^{\circ} 1$ & $\mathbf{N}^{\circ} 3$ & Ref \\
\hline 0 & 17.3 & 25.6 & 52.8 & 20.3 \\
\hline 15 & 18.45 & 27.5 & 56.32 & 22.2 \\
\hline 30 & 18.67 & 26.98 & 56.17 & 21.17 \\
\hline 60 & 17.33 & 26.55 & 48.52 & 21.54 \\
\hline
\end{tabular}

Table 3. Results of variation of the mass.

\begin{tabular}{|c|c|c|c|c|}
\hline \multicolumn{5}{|c|}{ Variation of the mass/surf $\left(\mathrm{mg} / \mathrm{cm}^{2}\right)$ in tap water } \\
\hline Time (mn) & Alupur & $\mathrm{N}^{\circ} \mathbf{1}$ & $\mathrm{N}^{\circ} 3$ & Ref \\
\hline $0-15$ & 0.017 & 0.021 & 0.042 & 0.036 \\
\hline $0-30$ & 0.029 & 0.042 & 0.063 & 0.073 \\
\hline $0-60$ & 0.038 & 0.063 & 0.083 & 0.085 \\
\hline \multicolumn{5}{|c|}{ Variation of the mass/surf $\left(\mathrm{mg} / \mathrm{cm}^{2}\right)$ in salt tap water $(3 \mathrm{~g} / \mathrm{l})$} \\
\hline Time (mn) & Alupur & $\mathbf{N}^{\circ} \mathbf{1}$ & $\mathbf{N}^{\circ} 3$ & Ref \\
\hline $0-15$ & 0.061 & 0.021 & 0.031 & 0.051 \\
\hline $0-30$ & 0.088 & 0.042 & 0.063 & 0.101 \\
\hline $0-60$ & 0.135 & 0.063 & 0.083 & 0.140 \\
\hline \multicolumn{5}{|c|}{ Variation of the mass $/ \mathrm{surf}\left(\mathrm{mg} / \mathrm{cm}^{2}\right)$ in vegetal oil } \\
\hline Time (mn) & Alupur & $\mathrm{N}^{\circ} 1$ & $\mathbf{N}^{\circ} 3$ & Ref \\
\hline $0-15$ & - & - & - & - \\
\hline $0-30$ & - & - & - & - \\
\hline $0-60$ & - & - & - & - \\
\hline
\end{tabular}

the original surface and are given by the following Table 3.

\subsection{Chemical Analysis of Substrates}

The chemical analysis of the substrates after the tests reveals mainly the presence of aluminum ions (Tables 4 and 5).

\section{Analysis of Results}

The corrosion behavior of aluminum widely used in industry materials alloys has been studied extensively in connection with their applications (transport, energy, engineering, etc.) but also in part of basic research. These
Table 4. The colorimetry test results.

\begin{tabular}{|c|c|c|c|c|}
\hline \multicolumn{5}{|c|}{ Ions detection by colorimetry after $60 \mathrm{mn}$} \\
\hline \multicolumn{5}{|c|}{ Tap water: pH ( 7.6 before - 9.2 after) } \\
\hline & $\mathbf{A l}^{3+}(\mathrm{mg} / \mathrm{l})$ & $\mathrm{Cl}^{-}(\mathrm{mg} / \mathrm{l})$ & $\mathbf{F e}^{2+}(\mathrm{mg} / \mathrm{l})$ & $\mathbf{C u}^{2+}(\mathrm{mg} / \mathrm{l})$ \\
\hline Alupur & 4 & - & - & - \\
\hline $\mathbf{N}^{\circ} \mathbf{1}$ & 5 & - & - & - \\
\hline $\mathbf{N}^{\circ} 3$ & 6 & - & - & - \\
\hline Ref & 6 & - & - & - \\
\hline \multicolumn{5}{|c|}{ Salt tap water $3 \mathrm{~g} / \mathrm{l} \mathrm{pH}$ ( 6.2 before -8.6 after) } \\
\hline Alupur & 50 & 3000 & - & - \\
\hline Ech 01 & 50 & 3000 & - & - \\
\hline Ech 03 & 60 & 3000 & - & - \\
\hline Ref & 50 & 3000 & - & - \\
\hline \multicolumn{5}{|c|}{ Vegetal oil } \\
\hline Alupur & - & - & - & - \\
\hline Ech 01 & - & - & - & - \\
\hline Ech 03 & - & - & - & - \\
\hline Ref & - & - & - & - \\
\hline
\end{tabular}

Table 5. The spectrometry test results.

\begin{tabular}{|c|c|c|c|c|}
\hline \multicolumn{5}{|c|}{ Ions detection by spectrometry after $60 \mathrm{mn}$} \\
\hline \multicolumn{5}{|c|}{ Tap water: pH ( 7.6 before - 9.2 after) } \\
\hline & $\mathbf{A l}^{3+}(\mathrm{mg} / \mathrm{l})$ & $\mathrm{Cl}^{-}(\mathrm{mg} / \mathrm{l})$ & $\mathbf{F e}^{2+}(\mathrm{mg} / \mathrm{l})$ & $\mathbf{C u}^{2+}(\mathrm{mg} / \mathrm{l})$ \\
\hline Alupur & $3.1 \pm 0.08$ & - & - & - \\
\hline $\mathbf{N}^{\circ} \mathbf{1}$ & $4.1 \pm 0.1$ & - & - & - \\
\hline $\mathbf{N}^{\circ} 3$ & $4.8 \pm 0.12$ & - & - & - \\
\hline Ref & $4.5 \pm 0.12$ & - & - & - \\
\hline \multicolumn{5}{|c|}{ Salt tap water $3 \mathrm{~g} / \mathbf{l} \mathrm{pH}$ ( 6.2 before - 8.6 after) } \\
\hline Alupur & $27 \pm 1.4$ & $3000 \pm 150$ & - & - \\
\hline $\mathbf{N}^{\circ} \mathbf{1}$ & $27 \pm 1.4$ & $3000 \pm 150$ & - & - \\
\hline $\mathrm{N}^{\circ} 3$ & $29 \pm 1.5$ & $3000 \pm 150$ & - & - \\
\hline Ref & $31 \pm 1.6$ & $3000 \pm 150$ & - & - \\
\hline \multicolumn{5}{|c|}{ Vegetal oil } \\
\hline Alupur & - & - & - & - \\
\hline $\mathrm{N}^{\circ} \mathbf{1}$ & - & - & - & - \\
\hline $\mathrm{N}^{\circ} 3$ & - & - & - & - \\
\hline Ref & - & - & - & - \\
\hline
\end{tabular}

studies, however, are significantly lower in the food area of concern. Moreover, in this case, the work focus on the food brought into contact with the materials from which it seeks to assess the transfer. The authors are rarely are concerned about the degradation of the material itself view through the concepts of materials science, so that linking the two aspects of the problem is quite innovative.

\subsection{Corrosion of Aluminum}

The aqueous corrosion has been extensively studied as responsible for much of the degradation of materials. It 
starts, for aluminum and its alloys by the attack of the protective film of alumina $\left(\mathrm{Al}_{2} \mathrm{O}_{3}\right)$ which covers these materials spontaneously exposed to the open air [6].

For pure aluminum, this layer is continuous and even tends to thicken when it is immersed in boiling water. This is the bohemitage an operation performed to treat superficially industrial aluminum $\left(\mathrm{Al}_{2} \mathrm{O}_{3}\right.$ formation of boehmite, $\mathrm{H}_{2} \mathrm{O}$ ). In the presence of $\mathrm{Cl}$ ions, which are found for example in tap water [7] (less than $200 \mu \mathrm{g} / \mathrm{l}$ ) at the base of our corrosive solutions, the protective layer may disappear locally [8], putting bare aluminum which becomes an anode.

It produces an aqueous corrosion and pitting as described by C. Vargel [6] in his work on the behavior of aluminum and its alloys. This mechanism is governed by the concentration of $\mathrm{H}^{+}$ions of the solution, that is to say the $\mathrm{pH}$ and the electrical potential $\mathrm{E}$ of the workpiece relative to the solution [2].

\subsection{Corrosion of Artisanal Aluminum Alloys}

In our aluminum alloys, the microstructure consists of a mixture of phases [1], comprising the majority of primary aluminum crystals, and intermetallic compounds of silicon. The different phases with different corrosion potentials $[9,10]$, a galvanic coupling is established between the various components of the structure, and the anodic zones go into solution. Then degradation of the material is manifested by the appearance and development of pitting. Intermetallic compounds and silicon are located at the grain boundaries of crystals of primary aluminum, is called "intergranular corrosion" $[9,10]$, which can be activated by the presence of $\mathrm{Cl}^{-}$ions.

We show that aluminum corrodes preferentially in silicon and intermetallic compounds (Figures 2 and 3) and confirm, from this point of view, the mechanism of corrosion by galvanic coupling in aqueous media of different phases present in the industrial aluminum alloys observed by different authors [9-12].

Other authors [13] noted, however, the different be-

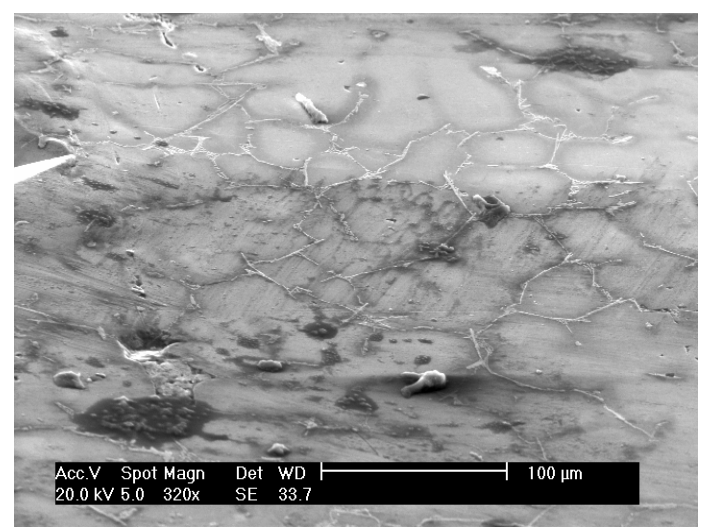

havior of Mg-rich precipitates which anodic compared to aluminum, are dissolved. Magnesium is associated with zinc in the compounds of $\mathrm{MgZn}_{2}$ type, these two elements will thus go into solution.

Thus, in all scenarios, the attack on the interface or aluminum-silicon-aluminum intermetallic compounds will lead to a loosening of the latter, which will be incorporated into foods in their solid form.

From the above analysis we can now draw the following conclusions:

The study of the corrosion of metals by food environments becomes complicated because of the wide variety of chemical species they contain species varies according to the origin of the product, the method of preparation and cooking of food etc. It is therefore very difficult to control all of these factors to have a stable and reproducible environment in testing and comparing the test results with those obtained by other authors.

The roughness parameter $\mathrm{R}_{\mathrm{q}}$ measured on the rough surface polishing (initial state), on the order of thirty nanometers comes after corrosion at a value of $500 \mathrm{~nm}$, or 17 times more. This strongly supports the observations made through a microscope.

\subsection{Loss of Mass of Samples}

Changes in mass loss of samples in different areas of corrosion show the same general shape revealing a first stage (from 0 to $30 \mathrm{~min}$ ) during which the mass loss is rapid, followed by a second stage where the evolution the mass change according of time is much lower (Table 6).

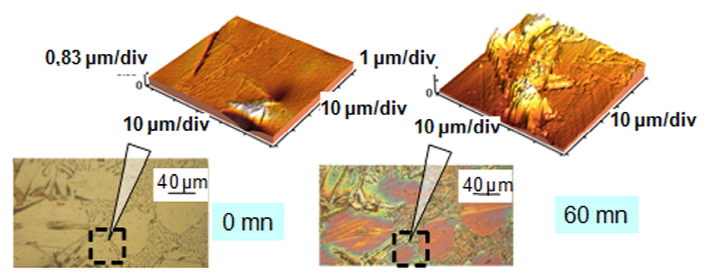

Figure 2. Micrograph and AFM before and after test in salt tap water.

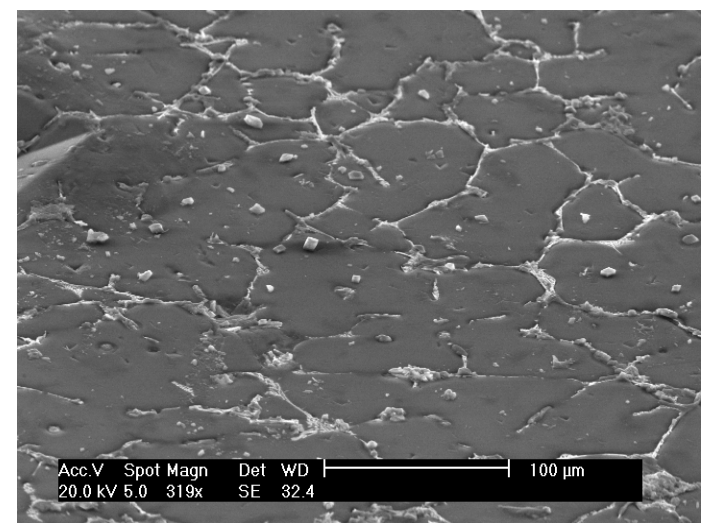

Figure 3. Photos of SEM before and after $30 \mathrm{mn}$ in salt tap water. 
Table 6. Variationop results.

\begin{tabular}{ccccc}
\hline \multicolumn{5}{c}{ Mass varation in tap water $\mathbf{m g} / \mathbf{c m}^{\mathbf{2}} \cdot \mathbf{h}( \pm 0.02)$} \\
\hline & Alupur & $\mathbf{N}^{\circ} \mathbf{1}$ & $\mathbf{N}^{\circ} \mathbf{3}$ & $\mathbf{R e f}$ \\
\hline $0-15 \mathrm{mn}$ & 0.06 & 0.08 & 0.16 & 0.14 \\
$15-30 \mathrm{mn}$ & 0.05 & 0.08 & 0.08 & 0.14 \\
$30-60 \mathrm{mn}$ & 0.02 & 0.04 & 0.04 & 0.02 \\
\hline
\end{tabular}

This high rate of mass loss at the beginning of the test is mainly due to the detachment of some solid particles of the unpolished surface samples from the foundry operation and not removed by the cleaning operations (finish), but also pitting whose development is fast enough early in the test following the containment of corrosion products (injections by electrolytic potential difference) [6].

These are pitting and intergranular corrosion that justify a higher speed in the sample $\mathrm{N}^{\circ} 3$, which has the highest rate of silicon.

The second stage does not show significant differences (due to uncertainties) between the corrosion rates.

The mass loss seems related to the rate of silicon (Figure 4). This is explained by the phenomenon of receding needles of silicon or silicon-based intermetallic we discussed above with the results of the micrograph. This trend is also observed in the OS environment.

\subsection{The Transfer of Ions to the Substrates}

The results show a significant presence of aluminum ions in the substrates. This is also explained by the principle of receding intermetallic presented with the results of the micrograph.

This presence poses the problem of the toxicity of substrates for man. This study needs to be conducted in collaboration with specialized medical departments.

\section{Conclusions}

Recycled handmade products in Senegal alloys do not compliant with standards [1]. The experiences we have just completed shows that degradation is significant in tap water and salt water $(3 \mathrm{~g} / \mathrm{l})$ and negligible in vegetable oil. The observed mechanism is intergranular corrosion which preferentially attacks the aluminum around the intermetallic grains. Ultimately we have a loosening of these grains that eventually get into the substrate. This mechanism explains the loss of mass during the tests and the presence of aluminum ions at different levels in the substrates.

We also note that the mass loss is a function of the silicon content and is much more pronounced in the saline environment. This is mainly due to the presence of $\mathrm{Cl}^{-}$ ions which promotes corrosion of aluminum by destroying its protective layer [6]. However it is not more

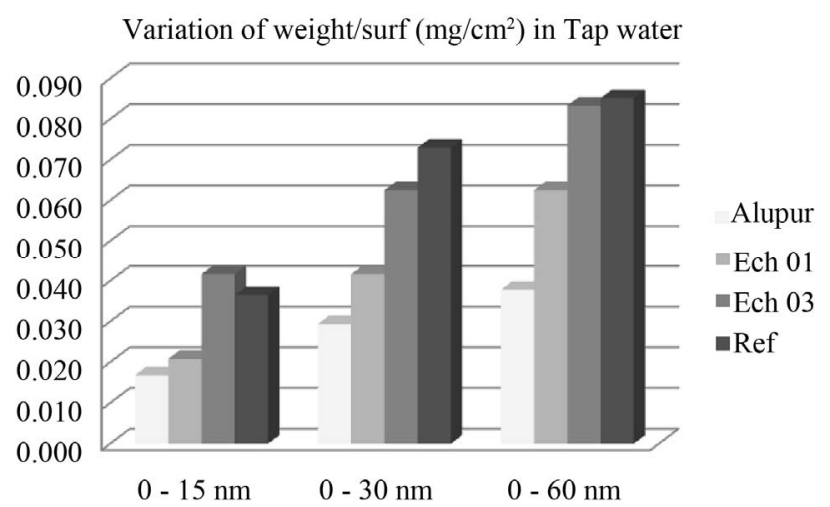

Figure 4. Variation of mass in tap water.

important than the reference sample, which meets the standard. It would be interesting to see the effect of the ingestion of these substrates on human health. This study could be conducted by an interdisciplinary team including specialists in medicine.

\section{REFERENCES}

[1] M. B. Ndiaye, S. Bec, B. Coquillet and I. K. Cissé "Analysis of Cooking Utensils Containing Aluminum Scrap in Senegal," Research Journal of Applied Sciences Engineering and Technology, Vol. 4, No. 4, 2012, pp. 367370.

[2] D. Landolt, "Corrosion et Chimie des Surfaces des Métaux," Polytechnic University Presses and Romandes, Lausanne, 2003.

[3] W. Huppatz, "Well-Tried Methods of Corrosion Investigation and Corrosion Testing for Aluminum Materials and Aluminum Components," Materials and CorrosionWerkstoffe und Korrosion, Vol. 53, No. 9, pp. 680-691. http://dx.doi.org/10.1002/1521-4176(200209)53:9<680:: AID-MACO680 $>3.0 . \mathrm{CO} ; 2-\mathrm{X}$

[4] J. R. Davis, "Corrosion of Aluminum and Aluminum Alloys (\#06787G)," ASM International, Almere, 1999.

[5] G. Charlot, " Analyse Qualitative rapide des Cations et des Anions," Dunod, Paris, 1963.

[6] C. Vargel, "Le Comportement de l'Aluminium et de ses Alliages," Dunod, Paris, 1979.

[7] Decree No. 2001-1220 of 20-12-2001 Relating to the Regulation of safe Drinking Water (Application on 24 December 2003).

[8] M. Ergun, M. Balbasi and A. Tosun, "Correlation Model of Aluminium Pitting Potential Variation with Environmental Conditions," British Corrosion Journal, Vol. 32, No. 2, 1997, pp. 117-121. http://dx.doi.org/10.1179/000705997798114986

[9] R. P. Wei, C. M. Liao and M. Gao, "A Transmission Electron Microscopy Study of Constituent-Particle-Induced Corrosion in 7075-T5 and 2024-T3 Aluminium Alloys," Metallurgical and Material Transactions A, Vol. 29, 1998, pp. 1153-1160.

[10] P. S. Pao, C. R. Feng, J. J. Gill and K. K. Sankara, "Cor- 
rosion-Fatigue Crack Growth in Friction Stir Welded Al 7050," Scripta Materialia, Vol. 45, No. 5, 2001, pp. 605612. http://dx.doi.org/10.1016/S1359-6462(01)01070-3

[11] L. E. Fratila-Apachitei, I. Apachitei and J. Duszczyk, "Characterization of Cast Al-Si(Cu) Alloys by Scanning Kelvin Probe Force Microscopy," Electrochimica Acta, Vol. 51, No. 26, 2006, pp. 5892-5896.

[12] F. Andreatta, H. Terryn and J. H. W. De Wit, "Corrosion Behaviour of Different Tempers of AA7075 Aluminium
Alloy," Electrochimica Acta, Vol. 49, No. 17, 2004, pp. 2851-2862.

http://dx.doi.org/10.1016/j.electacta.2004.01.046

[13] V. Guillaumin and G. Mankowski, "Localized Corrosion of 6056 T6 Aluminium Alloy in Chloride Media," Corrosion Science, Vol. 42, No. 1, 2000, pp. 109-125. http://dx.doi.org/10.1016/S0010-938X(99)00053-0 